NASA Technical Memorandum 100782

\title{
Adhesion, Friction, and Micromechanical Properties of Ceramics
}

\author{
(NASA-TU-100782) ADEESION, FEICIION AND N88-17801 \\ VICRCHECHANTCAL EEOEEETIES CE CEFAMICS \\ (NASA) $24 \mathrm{~F} \quad \mathrm{CSCL} 11 \mathrm{C}$ \\ Unclas \\ G3/27 0124576
}

Kazuhisa Miyoshi

Lewis Research Center

Cleveland, Ohio

Prepared for the

15th International Conference on Metallurgical Coatings

sponsored by the American Vacuum Society

San Diego, California, April 11-15, 1988 


\title{
ADHESION, FRICTION, AND MICROMECHANICAL PROPERTIES OF CERAMICS
}

\author{
Kazuhisa Mi yoshi \\ National Aeronautics and Space Administration \\ Lewis Research Center \\ 21000 Brookpark Road \\ Cleveland, Ohio 44135
}

Phone 216-433-6078

Telex NASA CLV 98-5218

FAX 216-433-8000

\section{ABSTRACT}

The adhesion, friction, and micromechanical properties of ceramics, both in monolithic and coating form, are reviewed. Ceramics are examined in contact with themselves, other harder materials, and metals. For the simplicity of discussion, the tribological properties of concern in the processes are separated into two parts. The first part discusses the pull-off force (adhesion) and the shear force required to break the interfacial junctions between contacting surfaces. The role of chemical bonding in adhesion and friction, and the effects of surface contaminant films and temperature on tribological response with respect to adhesion and friction, are discussed.

The second part deals with abrasion of ceramics. Elastic, plastic, and fracture behavior of ceramics in solid state contact is discussed. The scratch technique of determining the critical load needed to fracture interfacial adhesive bonds of ceramic deposited on substrates is also addressed. 


\section{INTRODUCTION}

Ceramic materials are being used increasingly for machine elements in sliding or rolling contact. These elements include components of advanced engines: bearings, seals, gears, and tools used in metal shaping, such as cutting tools and extrusion dies. The successful use of ceramics in these applications is limited more often by tribological problems than by material properties or processing deficiencies (refs. 1 to 4). Clearly, there is a great need for a fundamental understanding of the surface interactions of ceramics with themselves and other materials (ref. 5).

Various deposition or surface modification techniques (especially the atomistic deposition processes by which surface films or surface layers of the most diverse composition and structure may be formed) have further enhanced interest in ceramic materials. Many of these films or layers are of materials which do not exist in the bulk state. There is a great opportunity to choose surfaces or surface layers with clearly specified strength and surface properties (refs. 6 and 7).

The objective of this paper is to review the adhesion, friction, and micromechanical properties of ceramics, the effect of surface contaminant films, the effect of temperature, and metal-to-ceramic interactions. Both monolithic ceramics and thin ceramic coating films will be discussed. Their tribological behavior involves many features similar to those of metals. Analogies with metals will be made where applicable.

\section{ADHESION AND FRICTION}

\section{Clean and Contaminated Surfaces}

The surfaces of ceramics usually contain, in addition to the constituent atoms, adsorbed films of water vapor or hydrocarbons that may 
have condensed from the environment. On oxide-ceramic materials an oxide layer may or may not be present. For example, oxygen is an integral part of the structure on aluminum oxide and ferrites, so an oxide surface layer may not be expected. Non-oxide ceramics, however, generally contain a layer of oxide beneath the layer of adsorbent film. Thus, the surfaces of silicon carbide and silicon nitride are covered with silicon oxides as well as a simple adsorbed film of oxygen (refs. 8 and 9 ).

In a vacuum environment, sputtering with rare gas ions or heating surfaces to very high temperatures can remove contaminants that are adsorbed on the surface of ceramics. Removing adsorbed films from the surfaces of ceramics and metals results in very strong interfacial adhesion when two such solids are brought into contact. If an atomically clean silicon carbide surface is brought into contact with a clean aluminum surface, the adhesive bonds formed at the silicon carbide-to-aluminum interface are sufficiently strong that the cohesive bonds in the aluminum are fractured and transferred to the silicon carbide surface (ref. 10).

Not only are the adhesion, friction, and micromechanical properties of metals and polymers affected by the presence of contaminant films (such as adsorbates and oxides), but also those of ceramic materials, both in monolithic and coating form, in contact with themselves or metals. Typical adhesion and friction results from hot-pressed polycrystalline silicon nitride and ion-beam-deposited boron nitride films in contact with metals are presented in figure 1. The pull-off force (adhesion) and coefficient of friction are strongly affected by adsorbates. The pull-off force and coefficient of friction for the sputter-cleaned surfaces are higher than those for the as-received surfaces. In other words, the presence of the 
adsorbates on the surface of the silicon nitride in monolithic form or of the boron nitride in coating form reduced the adhesion and shear strength of the contact area.

In contrast, oxygen exposures to clean metal and ceramic surfaces did strengthen the metal-to-ceramic adhesion (ref. 11). Exposing both metal and ceramic surfaces to oxygen under carefully controlled conditions, after sputtering with argon ions or heating in vacuum, results in the adsorption of oxygen which produces the following two effects: (1) The metal oxidizes and forms an oxide surface layer, and (2) the oxide layer increases the shear strength of the contact and the coefficients of friction (refs. 11 to 13). In these cases strong oxide-oxide bonding takes place at the interfaces, thereby raising the shear strength and the coefficient of friction.

Figure 1 also indicates that adhesion and friction forces for sputter-cleaned metal-ceramic couples were smaller for metals with a large component of $d$ electrons in the bond. This subject is discussed in somewhat greater detail in the next section.

\section{Chemical Bonding}

Pauling, in 1948, formulated a resonating-valence-bond theory of metals and intermetallic compounds in which numerical values could be placed on the bonding character of the various transition elements (ref. 14). Since the d-valence bonds are not completely filled in transition metals, they are responsible for such physical and chemical properties as cohesive energy, shear modulus, chemical stability, and magnetic properties. The greater the amount or percentage of $d$-bond character that a metal possesses, the less active is its surface. While 
there have been critics of this theory, it appears to be the most plausible explanation of the interfacial interactions of transition metals in contact with ceramics as well as with themselves (ref. 15).

When a transition metal is placed in contact with a ceramic material in an atomically clean state, the interfacial bonds formed between the metal and ceramic depend heavily on the character of the bonding in the metal. The data for the sputter-cleaned surfaces presented in figure 1 indicate a decrease in adhesion and friction with an increase in $d$-bond character, as predicted by Pauling's theory. Titanium and zirconium, which are chemically very active, exhibit very strong adhesive bonding to the ceramic. In contrast, rhodium and rhenium, which have a very high percentage of d-bond character, have relatively low adhesion and friction.

Today, virtually all the known elements are used to make ceramic materials and products. Probably the most widely used class of ceramic materials, however, is the oxides. Some precise experiments on shear strength of metal-to-sapphire contact were conducted by Pepper who used an ultra-high-vacuum apparatus and incorporated Auger electron spectroscopy (ref. 16). His study determined a correlation between the shear coefficients of the metal-to-sapphire contacts and the free energy of formation of the lowest metal oxide. For other oxide ceramics such as nickel-zinc ferrite and manganese-zinc ferrite in sliding contact with metals, a similar correlation between coefficient of friction and the free energy of formation of the lowest metal oxide is found (ref. 12). These correlations clearly indicate that the oxide-ceramic-to-metal bond at the interface is primarily a chemical bond between the metal atoms and the large oxygen anions in the oxide-ceramic surface. The strength of this 
bond was related to the oxygen-to-metal bond strength in the metal oxides (refs. 16 and 17 ).

\section{Temperature Effects}

An increase in surface temperature of a ceramic material tends to promote surface chemical reactions. These chemical reactions cause products to appear on the surface which can alter adhesion, friction, and wear (ref. 8). For example, when an as-received silicon carbide surface is heated in a vacuum, the principal contaminants (determined by $x$-ray photoelectron spectroscopy) on the as-received sintered polycrystalline silicon carbide surface are adsorbed carbon and oxygen, residual graphite, and silicon dioxide (fig. 2). The residual graphite on the silicon carbide surface was generated during fabrication in an argon atmosphere.

The adsorbed carbon contaminants disappear on heating to $400{ }^{\circ} \mathrm{C}$. Above $400^{\circ} \mathrm{C}$, primarily graphite and silicon dioxide are seen on the silicon carbide surface. The amount of silicon dioxide present on the surface decreases rapidly with increasing temperature in the range of 600 to $800^{\circ} \mathrm{C}$. At $800^{\circ} \mathrm{C}$, the silicon carbide-Si2p and $-\mathrm{C}_{1 \mathrm{~s}}$ peaks can be distinguished and are at a maximum intensity. Above $800^{\circ} \mathrm{C}$, the graphite concentration increases rapidly with an increase in temperature, whereas the silicon carbide concentration decreases rapidly in intensity at the silicon carbide surface. The surface of silicon carbide graphitizes predominantly at temperatures of 1000 to $1200^{\circ} \mathrm{C}$.

The coefficient of friction, for the sintered polycrystalline silcon carbide flat surfaces in sliding contact with an iron rider, as a function of sliding temperatures is indicated in figure 3 . The coefficient of friction, which remains low below $250^{\circ} \mathrm{C}$, can be associated with the 
presence of both carbon and graphite contaminants on the as-received specimen. The rapid increase in the coefficient of friction at $400^{\circ} \mathrm{C}$ can be attributed to (1) the absence of carbon contaminants, (2) the presence of increased silicon dioxide, (3) increased adhesion, and (4) increased plastic flow causing junction growth in the contact zone. The rapid decrease in friction above $800^{\circ} \mathrm{C}$ correlates with the graphitization of the silicon carbide surface.

\section{Microfracture Under Adhesive Conditions}

Adhesive wear occurs after adhesion takes place across an interface between two ceramic surfaces or a ceramic surface and another material. When an atomically clean silicon carbide flat surface is brought into contact with a clean metal rider or a clean silicon carbide rider, the adhesive bonds formed at the silicon carbide-to-metal interface or silicon carbide-to-silicon carbide interface are sufficiently strong that the cohesive bonds in silicon carbide may fracture (ref. 10). Tangential sliding motion results in the formation of cracks, fracture pits, and wear debris in and near the contact region of the silicon carbide surface. The presence of intrinsic defects such as voids, microcracks, and impurities in the surficial layers of the materials in contact will generally dictate the zones from which fractured debris and fracture pits are generated during sliding. The extent and distribution of such defects will also, to a large extent, determine the size of the wear particles generated. In order for this type of wear to occur, adhesion must first exist. Also, the fracture toughness of one of the two materials in contact must be less than the shear strength of the interfacial junction. 


\section{MICROMECHANICAL PROPERTIES}

Ceramics, in both monolithic and coating form, behave micromechanically in a ductile fashion up to a certain contact stress when they are brought into contact with themselves or other solids. Even at room temperature, ceramics such as aluminum oxide and silicon carbide behave elastically and plastically at low stresses under relatively modest conditions of rubbing contact; however they microfracture under more highly concentrated contact stresses (refs. 18 to 25). This microfracture, known as brittle fracture, is one of the most critical characteristics of a ceramic that must be considered in design for structural and tribological applications.

\section{Elasticity}

Ceramics behave elastically up to a certain contact pressure. For example, when boron nitride coated on a $440 \mathrm{C}$ bearing stainless steel flat is placed in contact with itself on a $440 \mathrm{C}$ stainless steel pin in vacuum, the coefficient of friction is not constant. It decreases as the load increases as shown in figure 4. To a first approximation for the load range investigated, the relation between coefficient of friction $\mu$ and load $W$ on logarithmic coordinates is given by an expression of the form:

$$
\mu=k W^{-1 / 3}
$$

The exponent arises from an adhesion mechanism for the surfaces in solid-state contact. The area of elastic contact can be determined by the elastic deformation (ref. 26). The friction is found to be a function of the shear strength of this elastic contact area.

A similar friction characteristic for monolithic silicon carbide in contact with diamond is presented in figure 5(a). When a silicon carbide 
surface is placed in contact with a diamond under relatively low contact pressure, elastic deformation can occur in both the silicon carbide and the diamond. With the initiation of tangential motion, sliding occurs at the interface. Under these low load conditions, neither groove formation due to plastic flow nor cracking of silicon carbide during sliding is observed (ref. 23).

Under the foregoing conditions, friction is a function of the shear strength of the elastic contact area, as indicated in figure 5(a). That is, the relation between coefficient of friction $\mu$ and load $W$ is that given by equation (1). Over the entire load range, the mean contact pressure ranges from $1.5 \times 10^{3}$ to $3.5 \times 10^{3} \mathrm{~N} / \mathrm{mm}^{2}$. The maximum pressure at the center of the contact area calculated from a Hertzian stress distribution will be $2.3 \times 10^{3}$ to $4.9 \times 10^{3} \mathrm{~N} / \mathrm{mm}^{2}$.

\section{Plasticity}

Most ceramics, both in monolithic and in coating form, deform in a ductile manner as the contact pressure is further increased. The increase in applied contact pressure, however, results in a complete reversal in friction characteristic with an applied load. Figure $5(b)$ reveals an entirely different mode of deformation and energy dissipation with an estimated maximum Hertzian contact stress ranging from $1.4 \times 10^{4}$ to $3.0 \times 10^{4} \mathrm{~N} / \mathrm{mm}^{2}$ in the contact area. Plastic deformation occurs in the silicon carbide, causing permanent grooves during sliding, but there is little or no evidence of very small cracks being generated in the silicon carbide. The diamond indents the silicon carbide without suffering any permanent deformation to itself. The frictional energy dissipated during sliding following solid-state contact is due to shearing at the interface 
and to plastic deformation of the silicon carbide (i.e., plowing of silicon carbide by the diamond). The relation between coefficient of friction $\mu$ and load $W$ now takes the form $\mu=k W^{0.3-0.4}$. The exponent depends on the crystallographic orientation of the single-crystal silicon carbide.

When a much higher contact pressure is provided, ceramics behave in a brittle fashion (fig. $5(\mathrm{c})$ ). This subject will be discussed in the section Fracture.

Similar contact and friction characteristics for diamond on boron nitride films also occur (refs. 24 and 25). At certain ioads, the sliding action of the diamond results in a permanent groove in the boron nitride films deposited on both metallic and nonmetallic substrates.

Figure 6 presents data obtained about widths of plastically deformed grooves in boron nitride films on $440 \mathrm{C}$ stainless steel substrate. Comparative data for uncoated $440 \mathrm{C}$ stainless steel are also presented. When the width of resulting scratch $D$ for the boron nitride films is plotted against load $W$ on logarithmic coordinates, the data can be expressed as $W=k D^{n}$. This is Meyer's law, shown in figure 6 . The portion $L M$ for boron nitride film or portion $L^{\prime} M^{\prime}$ for uncoated $440 C$ stainless steel is considered to be composed of approximately straight portions of transitional slopes of 2.6,2 5, and 2.2. The portion MN for boron nitride film or $M^{\prime} N^{\prime}$ for uncoated $440 \mathrm{C}$ stainless steel is a straight line of slope 2. The portion $M N$ or $M^{\prime} N^{\prime}$ is the range over which Meyer's law is valid for boron nitride film and for uncoated $440 \mathrm{C}$ stainless steel. Here the Meyer index $n$ is constant and has the value 2. Thus, the boron nitride films on metallic and nonmetallic substrates behave 
plastically much like metals when they are brought into contact with hard solids such as diamond (ref. 27).

Mean contact pressure (yield pressure) $P$ during sliding may be defined by $P=W / A_{S} ; W$ is the applied load and $A_{S}$ is the projected contact area given $A_{S}=\pi D^{2} / 8$. Only the front half of the $p$ in is in contact with the flat. The yield pressure over the contact area gradually increases until deformation passes to a fully plastic state. The mean contact pressure at a fully plastic state Pm increases by a factor of 2 with the presence of boron nitride film.

When the ioad exceeds a certain critical value, the sliding action of diamond on the monolithic silicon carbide and on the boron nitride film causes fracture in both specimens.

\section{Fracture}

When a much higher contact pressure due to highly concentrated stress in the contact area between the diamond and silicon carbide is provided, the sliding action produces gross surface and subsurface cracking as weil as plastic deformation (ref. 23). Under such conditions, wear debris particles and large fracture pits caused by cracking are observed. The area of a fracture pit is a few times larger than that of the plastically deformed groove. In this case, the coefficient of friction is also much higher (four times or more) than those in elastic and plastic contacts. (See fig. $5(c)$.) Although fracture and plastic deformation in silicon carbide are responsible for the friction behavior observed, most of the frictional energy dissipated during sliding is due to the fracturing of the silicon carbide. Therefore, the coefficient of friction is commonly 
influenced by the bulk properties of the ceramic such as fracture toughness and crystallographic orientation (refs. 28 to 30 and fig. $5(\mathrm{c})$ ).

For the boron nitride film deposited on metallic or nonmetallic substrates, failure occurs primarily in the film or at the interface between film and substrate (or both), when the film is critically loaded (refs. 24 and 25). It is interesting that in figure 6 the portion FF, representing the condition of fracture where the load exceeded the critical load, is also roughly expressed by $W=k D^{n}$. The fractured scratch for the boron nitride film on the substrate is almost as wide as the scratch for the uncoated metallic material used for the substrate. This evidence confirms that cracks are generated from the contact area rather than from the free surface of the film. It suggests that the substrate is responsible not only for controlling the critical load which will fracture the boron nitride film but also for the extent of fracture as well. Furthermore, the critical load required to fracture a ceramic film on a substrate can be determined by measurements of scratch width.

Acoustic Emission and Friction Force

Investigators detected released acoustic emissions when the intrinsic cohesive bonds in ceramic coating film and/or the adhesive bonds between the film and substrate are broken and a new surface created. The pattern and intensity of the acoustic emissions depend on the nature of the disturbance; that is, plastic flow, cracking, or flaking of fragments (refs. 6, 31, and 32).

Figure 7 presents typical acoustic emission traces and friction force traces for a boron nitride film deposited on a nonmetallic substrate. When the boron nitride film surface is brought into contact with a diamond pin 
under a small load (which is lower than the critical loads needed to fracture intrinsic cohesive bonds in the boron nitride film and adhesive bonds between the film and substrate) no acoustic emission is detected (fig. $7(a))$. The friction force trace is slightly fluctuating with no evidence of stick-slip behavior (fig $7(b)$ ). After the diamond has passed over the surface once, scanning electron microscopic examination of the wear track indicates that a permanent groove is formed in the boron nitride film, much like in metallic films under similar conditions (ref. 25). However, no cracking of the boron nitride film is observed with sliding. An increase in load to or above the critical loads needed to fracture the boron nitride film and the interfacial adhesive bonds between the film and the substrate, however, results in a small amount of cracking in and near the plastically deformed groove. The acoustic emission trace indicates evidence of a fluctuating acoustic emission signal output (fig. $7(c))$. Acoustic emission is observed when the siding appears to involve small amounts of cracking in addition to plastic flow. Such acoustic emission is due to the release of elastic energy when cracks propagate in the boron nitride film and in the substrate. The friction force trace measured at the load $9 \mathrm{~N}$ is characterized by randomly fluctuating behavior, but only occasional evidence of stick-slip behavior is observed (fig. $7(d)$ ). When a much higher load is applied to the boron nitride film, sliding action produces, in addition to plastic flow, locally gross surface and subsurface fracturing in the film and at the interface between the boron nitride and the substrate. In such cases acoustic emission traces are primarily characterized by chevron-shaped behavior (fig. 7(e)), while 
friction force is primarily characterized by a continuous, marked stick-slip behavior (fig. $7(f)$ ).

The behavior of acoustic emission is related to that of friction force. For example, at point I in figure $7(e)$ and ( $f$ ), the diamond rider comes to rest until the point II is reached. At point II, the rider is set into motion and slips, and will continue to move until point III is reached. At point II, acoustic emission is released because the slip action produces fracturing at the interface between the boron nitride film and the substrate. At point III, the rider comes to rest again. Thus, fracture in the film and at the interface between the boron nitride film and the substrate is responsible for the observed acoustic emission signal output and friction behavior.

Acoustic and friction measurements of the critical load required to fracture a ceramic film on a substrate agree well with those detected by optical and scanning electron microscopy of the scratches.

Figure 8 presents data for critical loads needed to fracture the boron nitride film and adhesive bonds between the film and substrate as determined by acoustic emission and friction force measurements. The critical load to fracture is related to hardness and strength of the substrate. The harder the metallic substrate or the greater the strength of the substrate, the higher the critical load.

\section{CONCLUDING REMARKS}

Based on fundamental studies conducted with both monolithic ceramics and ceramic coating films, the following observations can be made:

1. Surface films on ceramics affect their tribological behavior. For example, adsorbed carbon contaminants on a silicon carbide surface decrease 
interfacial bond strengths and, accordingly, friction; whereas oxygen, as a surface contaminant on metals in sliding contact with oxide ceramics, increases both adhesion and friction.

2. Heating of silicon carbide to high temperatures can result in the graphitization of the ceramic surface with the graphite film functioning to reduce adhesion and friction.

3. When ceramics are in contact with metals, surface chemistry is extremely important to friction and wear behavior. In the transition metals, the d-valence-bond character correlates directly with the coefficient of friction for ceramics in both monolithic and coating form. The higher the percentage of $d$-bond character, the lower the coefficient of friction is.

4. Ceramics, like metals, will deform elastically and plastically in the interfacial region between two solids in contact under load. Unlike metals, however, when the contact stress exceeds a certain critical value, fracture can occur. Acoustic and friction measurements of the critical load required to fracture a ceramic film on a substrate agree well with those detected by optical and scanning electron microscopy of the scratches. 


\section{REFERENCES}

1. H.E. Sliney, T.P. Jacobson, D. Deadmore, and K. Miyoshi, Ceram. Eng. Sci. Proc., 7 (1986) 1039-1051.

2. R.W. Rice, Ceram. Eng. Sci.Proc., 6 (1985), 940-958.

3. P. Sutor, Ceram. Eng. Sci. Proc., 6 (1985), 963-964.

4. T.F.J. Quinn. Wear, 100 (1984), 399-436.

5. D.H. Buckley and K. Miyoshi, Ceram. Eng. Sci. Proc., 6 (1985), 919-939.

6. H.E. Hintermann, Wear, 100 (1984), 381-397.

7. D. Tabor, in W.R. Loomis (ed.), New Directions in Lubrication, Materials, Near and Surface Interactions: Tribology in the 80's, Noyes Publications, Park Ridge, NJ, 1985, pp. 1-17.

8. K. Miyoshi, D.H. Buckley, and M. Srinivasan, Am. Ceram. Soc. Bull. 62 (1983), 494-500.

9. T.E. Fischer and H. Tomizawa, Wear 105, (1985), 29-45.

10. K. Miyoshi and D.H. Buckley, ASLE Trans. 22 (1979), 245-256.

11. S.V. Pepper, J.Appl. Phys., 47 (1976), 2579-2583.

12. K. Miyoshi and D.H. Buckley, Ceram. Eng. Proc., 4 (1983), 674-693.

13. K. Miyoshi, D.H. Buckley, and T. Spalvins, J. Vac. Sci. Technol. A., 3 (1985), 2340-2344.

14. L. Pauling, Proc. R. Soc. London A. 196, (1949), 343-362.

15. K. Miyoshi and D.H. Buckley, Wear, 77 (1982), 253-264.

16. S.V. Pepper, J.App1. Phys., 47 (1976), 801-808.

17. K.H. Johnson and S.V. Pepper, J. Appl. Phys. 53 (1982), 6634-6637.

18. R.P. Steijn, J.Appl. Phys., 32 (1961), 1951-1958.

19. R.P. Steijn, J.Appl. Phys., 34 (1963), 419-428.

20. R.P. Steijn, Wear, 7 (1964), 48-66.

21. R.P. Steijn, ASLE Trans., 12 (1969), $21-33$. 
22. K.F. DuFrane and W.A. Glaeser, Study of Rolling-Contact Phenomena in Magnesium Oxide, NASA Contr. Rept. CR-72295, 1967 (NASA Lewis Research Center).

23. K. Miyoshi and D.H. Buckley, ASLE Trans., 22 (1979) pp. 79-80.

24. K. Miyoshi, D.H. Buckley, S.A. Alterovitz, J.J. Pouch and D.C. Lui, in Tribology--Friction, Lubrication and Wear: Fifty Years On, Vol. 11., Proc. Int. Conf., London, July 1981, Mechanical Engineering Publications, London, 1987, pp. 621-628.

25. K. Miyoshi, D.H. Buckley, J.J. Pouch, S.A. Alterovitz, and H.E. Sliney, Mechanical strength and tribological behavior of ion-beam deposited boron nitride films on non-metallic substrates, NASA Tech. Memo. TM-89818, 1987 (NASA Lewis Research Center).

26. F.P. Bowden and D. Tabor, The Friction and Lubrication of Solids-Part II, Clarendon Press, Oxford, 1964, pp. 158-185.

27. D. Tabor, The Hardness of Metals, Clarendon Press, Oxford, 1951, pp. $6-18$.

28. H. Isigaki and $K$. Miyoshi, Proceddings of the 6th International Conference on Production Engineering, Osaka, 1987, pp. 661-666.

29. D.H. Buckley and K. Miyoshi, Wear, 100 (1984), 333-353.

30. K. Miyoshi and D.H. Buckley, Wear, 75 (1982), 253-268.

31. H.E. Hintermann, in R.K. Viswanadham, D.J. Rowcliffe, and J. Gorland (eds.), Science of Hard Materials, Plenum New York, 1983, pp. 357-394.

32. P.A. Steinmann and H.E. Hintermann, J. Vac. Sci. Technol. A., 3 (1985), 2394-2400. 


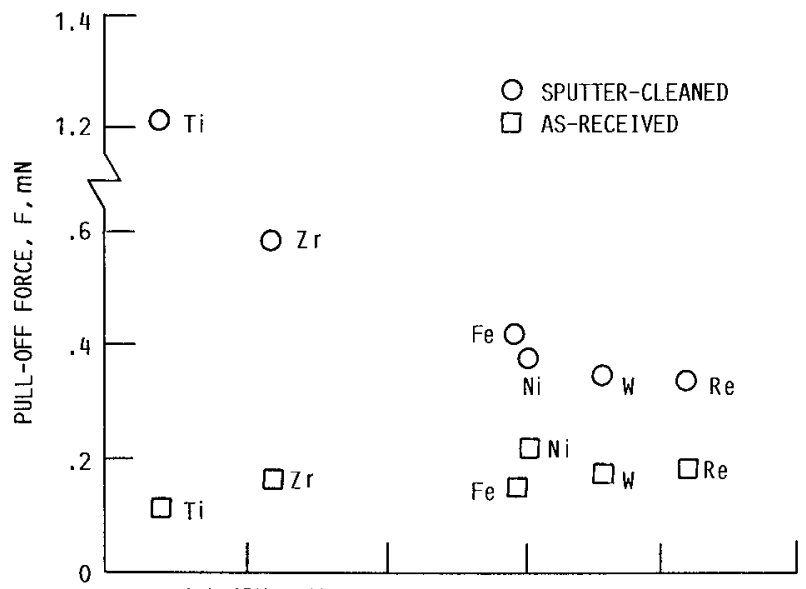

(a) ADHESION OF MONOLITHIC SILICON NITRIDE,

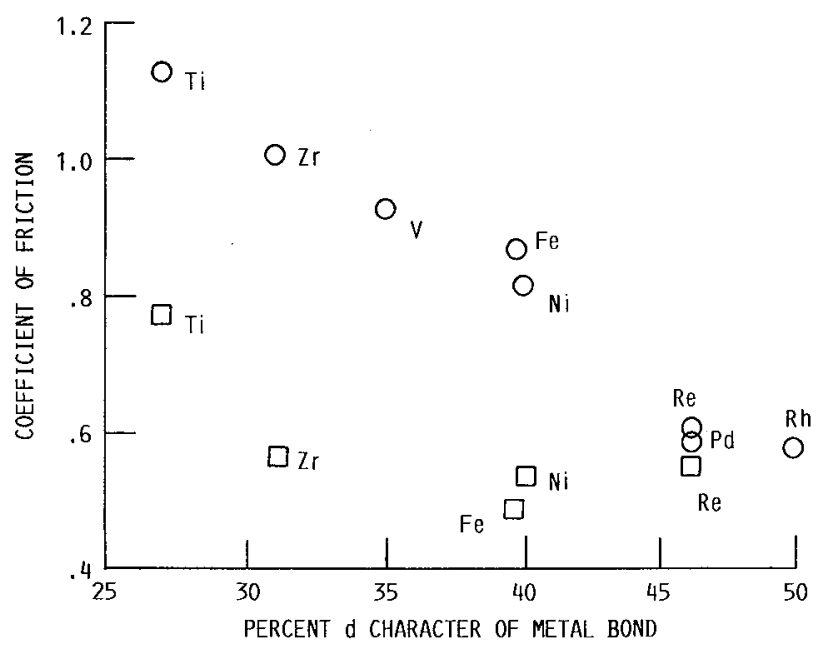

(b) FRICTION OF ION-BEAM-DEPOSITED BORON NITRIDE FILM. FIGURE 1. - PULL-OFF FORCE (ADHESION) AND COEFFICIENT OF FRICTION AS A FUNCTION OF THE PERCENTAGE d-BOND CHARACTER OF METALS IN CONTACT WITH CERAMICS IN A VACUUM. 


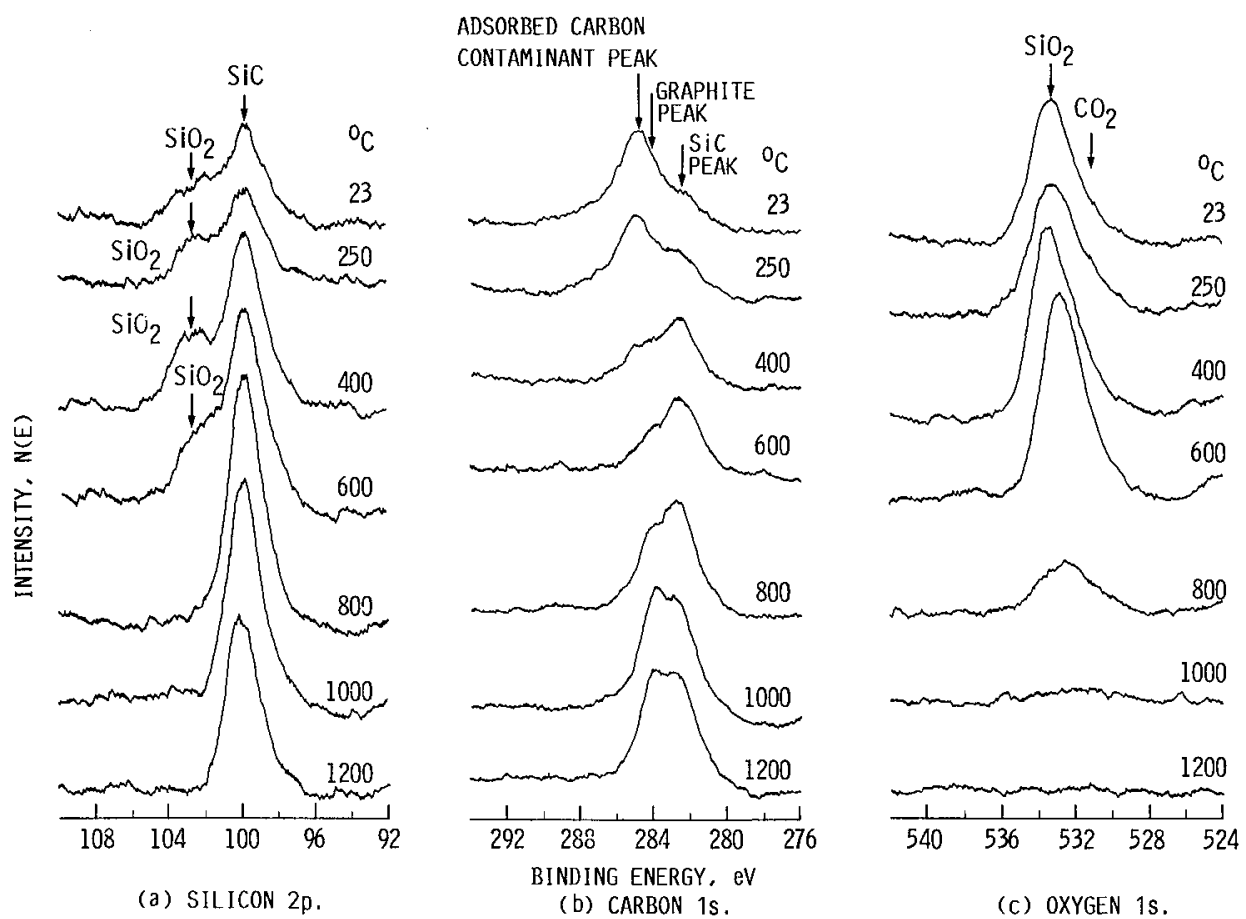

FIGURE 2. - REPRESENTATIVE XPS PEAKS FROM SINTERED POLYCRYSTALLINE SILICON CARBIDE SURFACE. PREHEATED AT TEMPERATURES INDICATED.

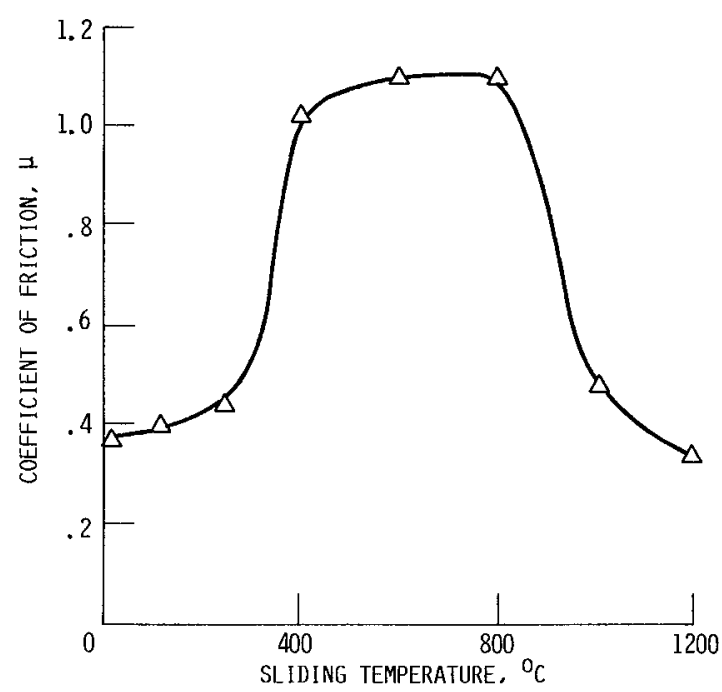

FIGIURE 3. - EFFECT OF TEMPERATURE ON COFFFICIENT OF FRICTION FOR SINTERED POLYCRYSTALLINE SILICON CARBIDE SURFACE SLIDING AGAINST AN IRON PIN IN VACUUM. 


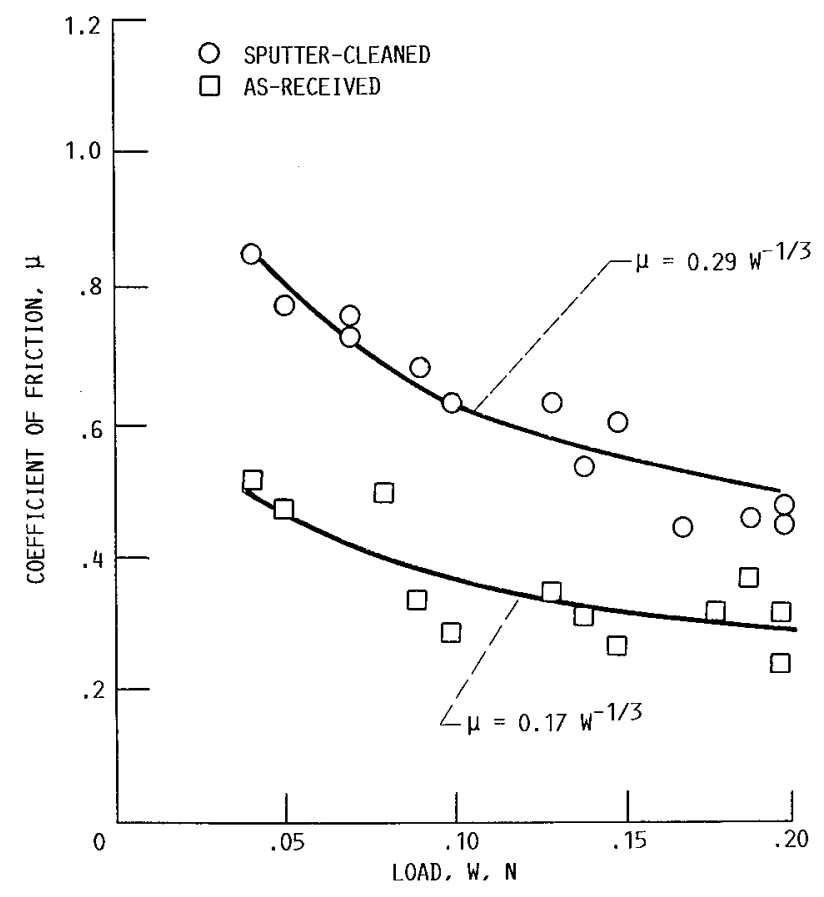

FIGURE 4. - COEFFICIENT OF FRICTION AS A FUNCTION OF LOAD FOR BORON NITRIDE FILM DEPOSITED ON HEMISPHERICAL PIN IN CONTACT WITH BORON NITRIDE FILM DEPOSITED ON A FLAT IN VACUUM.
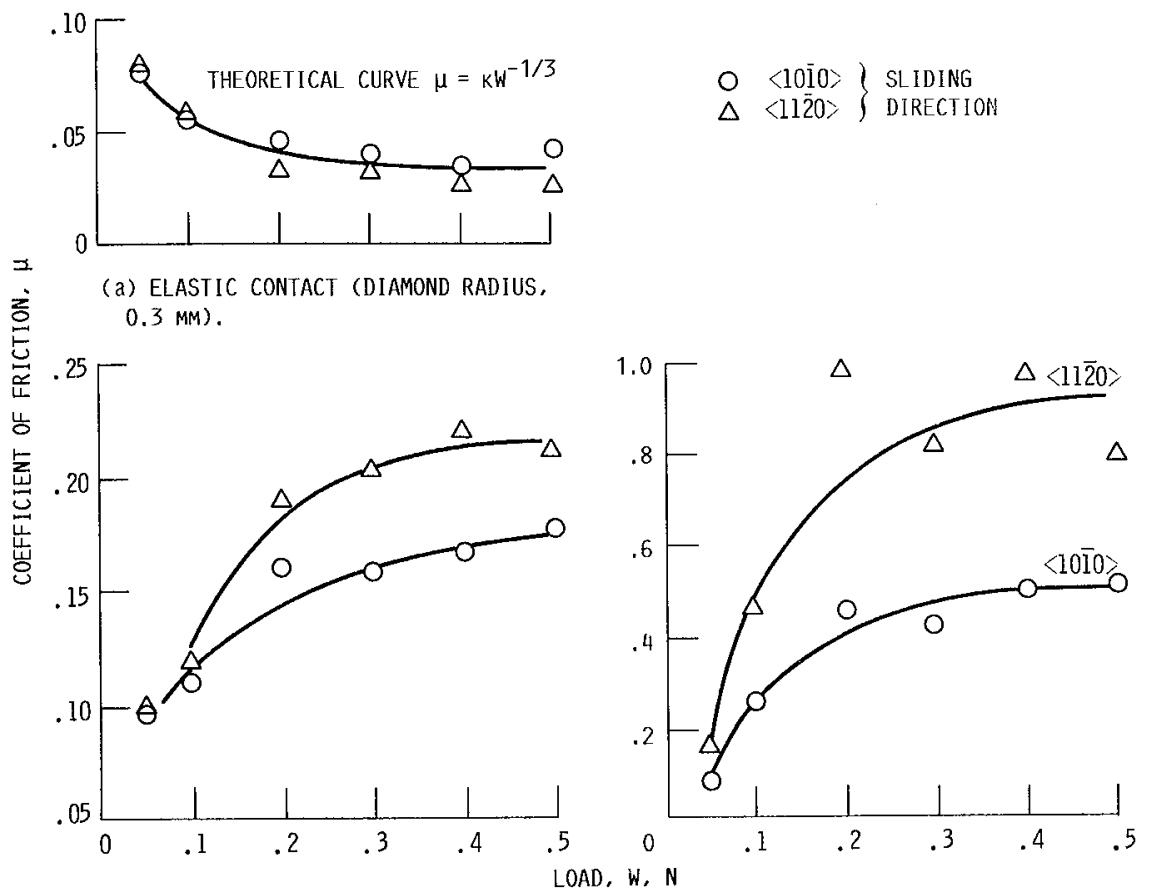

(b) PLASTIC CONTACT (DIAMOND RADIUS,

(c) SLIDING ACCOMPANIED BY GROSS FRACTURE (CONICAL DIAMOND WITH AN APICAL ANGLE OF $117^{\circ}$ ).

FIGURE 5. - COEFFICIENT OF FRICTION AS A FUNCTION OF LOAD FOR HEMISPHERICAL DIAMOND PINS OF DIFFERENT RADII AND A CONICAL DIAMOND PIN SLIDING ON A SINGLE-CRYSTAL. SILICON CARBIDE (0O01) SURFACE IN ARGON AT ATMOSPHERIC PRESSURE. 


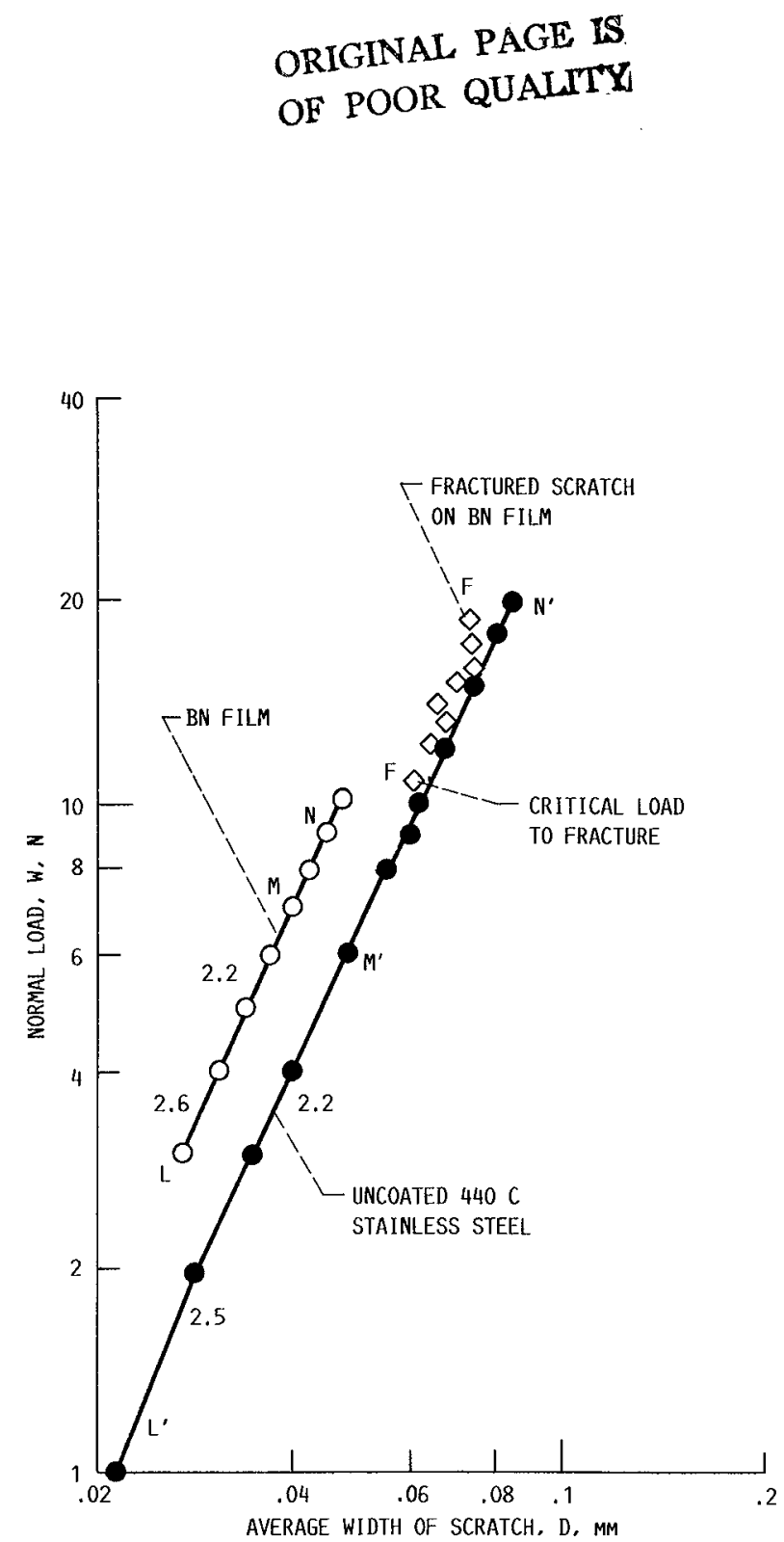

FIGURE 6. - SCRATCH WIDTH AS A FUNCTION OF LOAD FOR BORON NITRIDE FILM DEPOSITED ON 440 C STAINLESS STEEL IN CONTACT WITH A HEMISPERICAL DIAMOND PIN IN LABORATORY AIR.
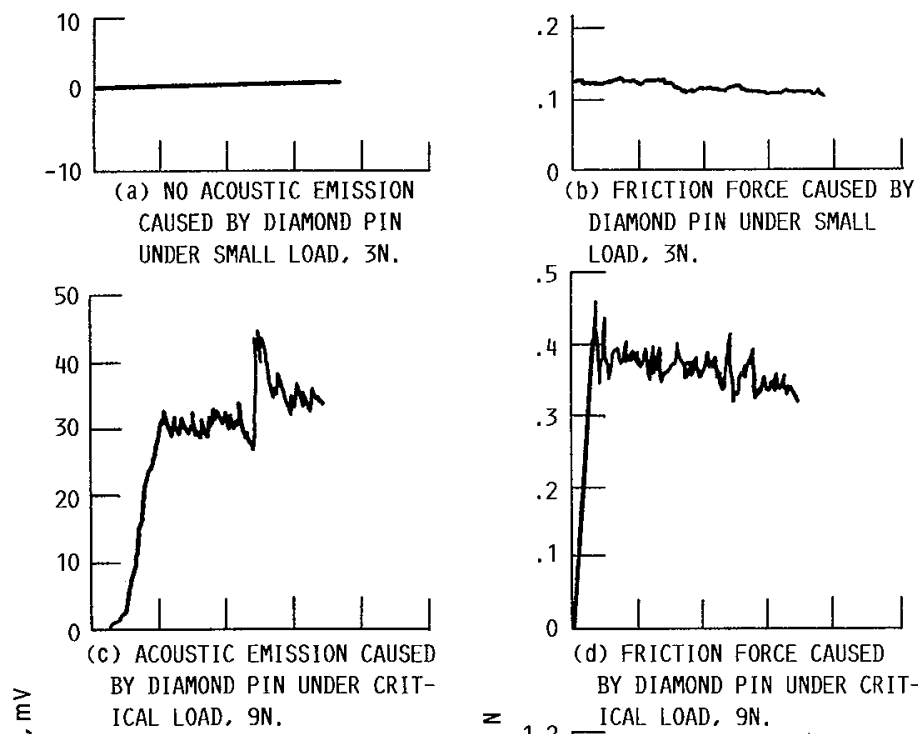

BY DIAMOND PIN UNDER CRIT-

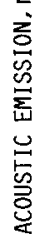

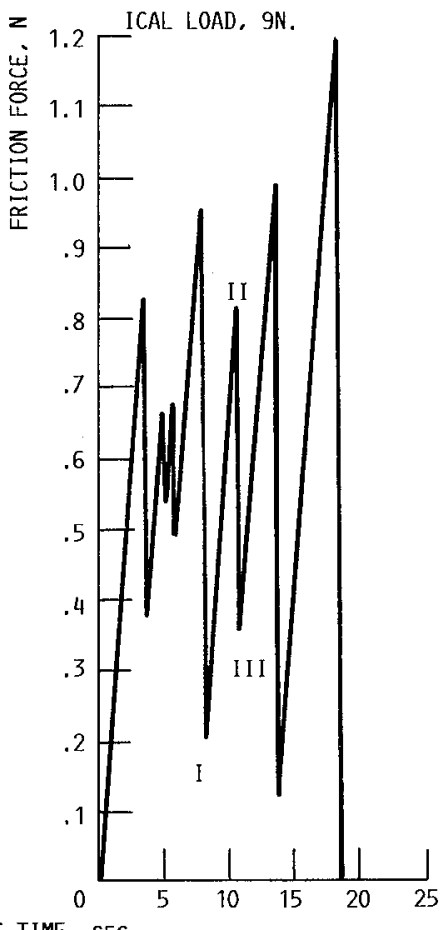

BY DIAMOND PIN UNDER MUCH (f) FRICTION FORCE CAUSED HIGHER LOAD, 12N.

(e) ACOUSTIC EMISSION CAUSED BY DIAMOND PIN UNDER MUCH HIGHER L.OAD, $12 \mathrm{~N}$.

FIGURE 7. - TYPICAL ACOUSTIC EMISSION TRACES AND FRICTION TRACES FOR A BORON NITRIDE FILM IN CONTACT WITH A HEMISPHERICAL DIAMOND PIN IN LABORATORY AIR. 

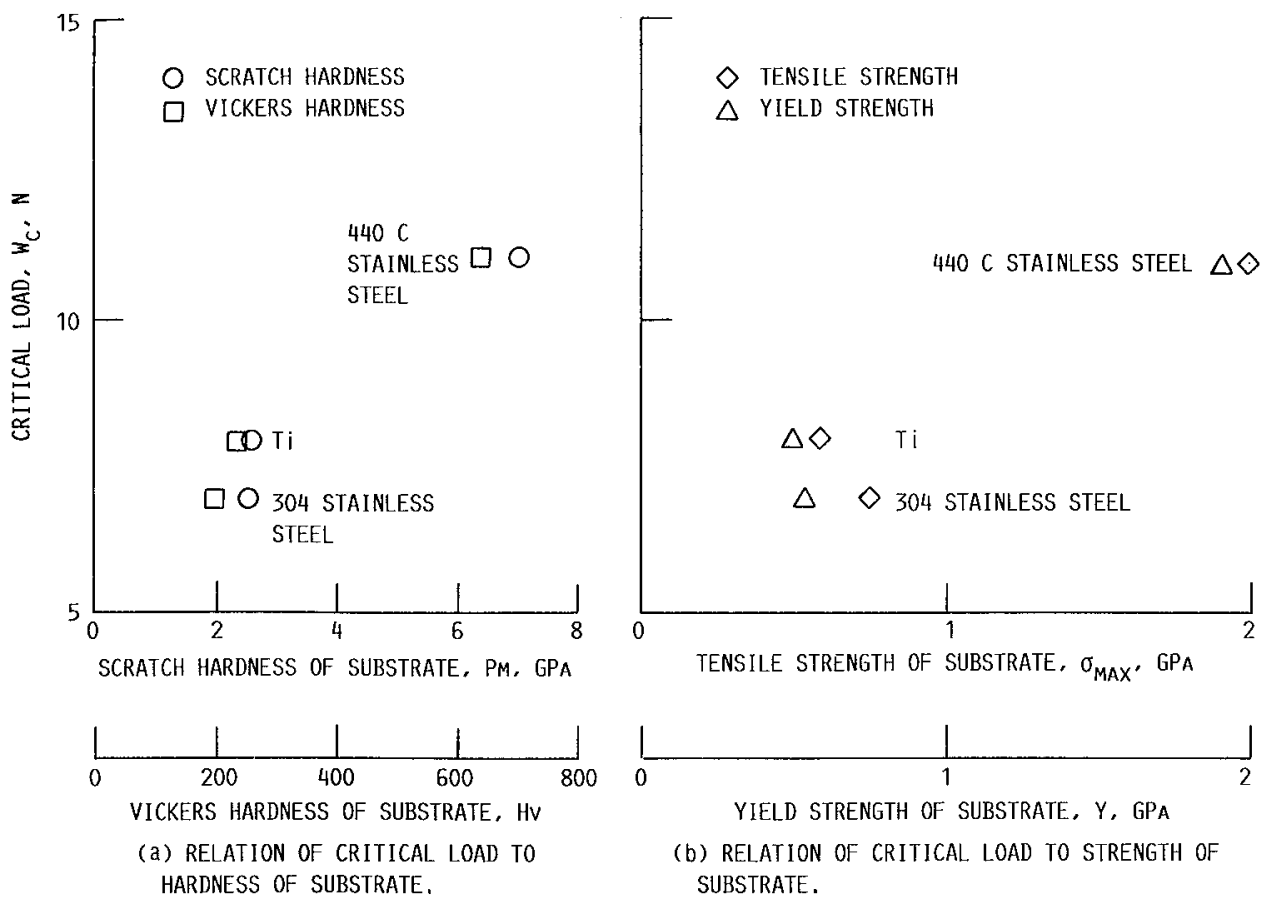

YIELD STRENGTH OF SUBSTRATE, $Y$, GPA

(b) RELATION OF CRITICAL LOAD TO STRENGTH OF SUBSTRATE.

FIGURE 8. - CRITICAL LOAD NEEDED TO FRACTURE BORON NITRIDE FILM AND INTERFACIAL ADHESIVE BONDS BETWEEN FILM AND SUBSTRATE IN SLIDING CONTACT WITH A HEMISPHERICAL DIAMOND PIN IN LABORATORY AIR. 


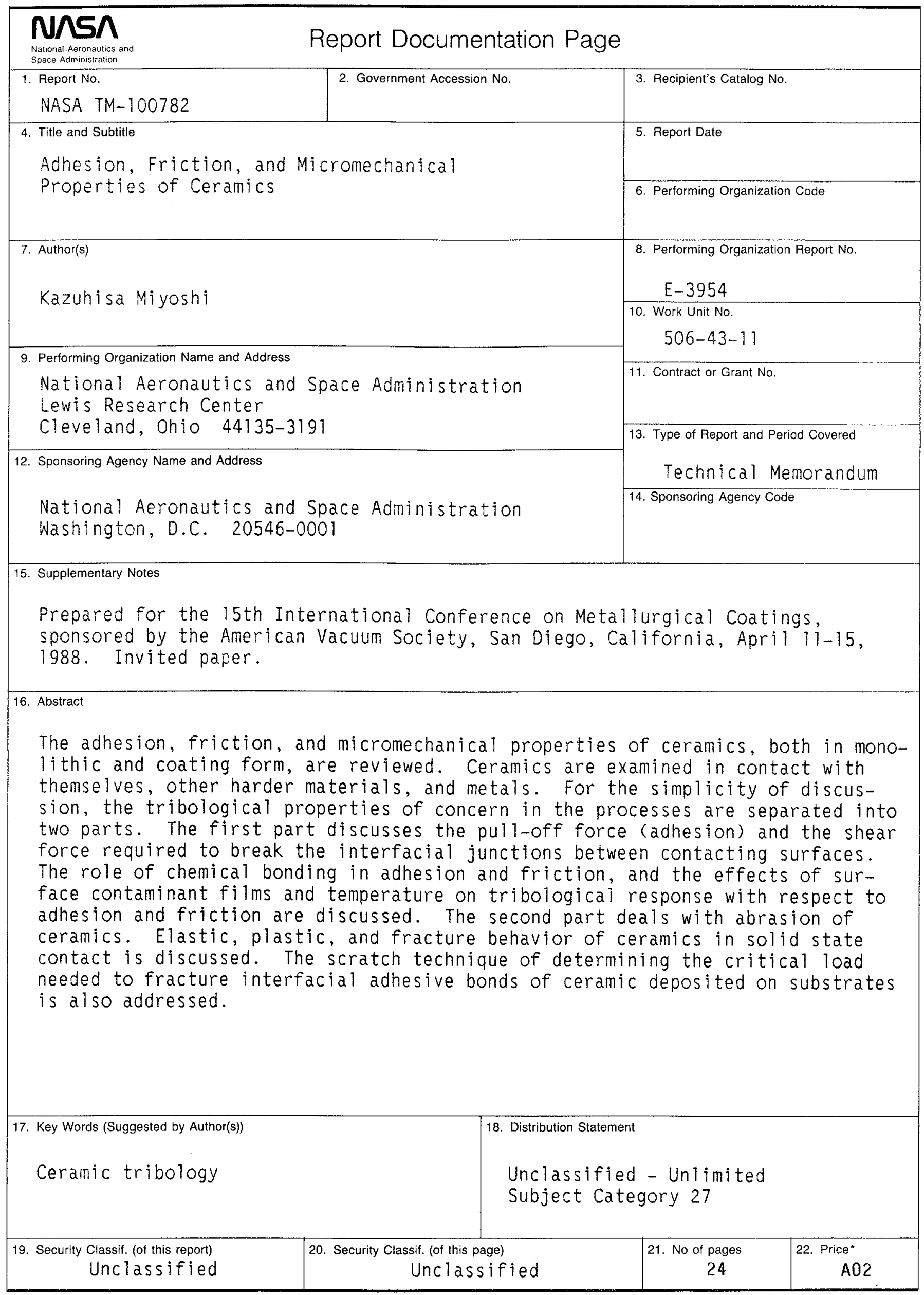


